A consideration of the above evidence would suggest that the organisms in the intestinal tract are in close rapport with those causing secondary infections in the lungs, and that stimulation of the one group may affect the other group as well. Also that the changes produced in the lungs by injection of gas may cause an excitation, not only of the tubercle bacilli and an outpouring of tuberculous toxins, but also an excitation of the secondary organisms in the lung which pour out their toxins and in turn set off those in the intestinal tract. The reverse process of this would also hold good. This is supported by the frequency with which intestinal symptoms are associated with increase in bronchitic symptoms in those subject to bronchitis, or with a mild bronchitis, and coryza in those who have no definite changes in their bronchial tubes. It would account moreover for the close relationship of excessive sulpho-ether excretions in cases with extensive secondary infection.

Finally, if there is any truth in the above observations and deductions, it becomes evident that to treat tuberculosis of the lungs as an isolated lesion, leaving out all consideration of the gastro-intestinal tract, is to treat a part only of the disease and to be therefore but inviting failure.

I would urge, therefore, that in investigating a case of pulmonary tuberculosis, in addition to the study of the chest symptoms and signs, of the bacteriological characters of the sputum, of the radiological appearances of the thorax, of evidences of tuberculosis elsewhere, it is necessary to investigate the condition of the intestinal system as regards stasis (and ptosis), and also, although it is a subject $I$ do not propose to discuss to-night, the functioning capacity of the endocrine glands.

May I, however, again emphasise what I said at first. What I have put before you about the sulpho-ethers and the secondary infections and tuberculosis, is offered tentatively. A larger mass of observations may show that my deductions are wrong. I hope at any rate that I may have made you realise that pulmonary tuberculosis is not a simple disease which can be regarded as a morbid change affecting the lungs only, but rather that the local pathology is a part only of a much more general pathology of the body.

\title{
HÆMOPTYSIS AND ITS TREATMENT.
}

\section{I.-CLASSIFICATION AND SOURCE.}

\section{By Cuive Riviere, M.D., F.R.C.P.}

Physician to City of London Hospital for Diseases of the Chest, Victoria Park, and East London Hospital for Children, Shadwell.

THE treatment of hæmoptysis cannot be considered a creditable chapter in the book of medicine, and we should most of us like to see it re-written -by an enemy for preference! In particular we should rejoice to lose the familiar faces of ergot, and of acetate of lead, tannic acid, perchloride of iron, et hoc genus omne-the children of false analogy and unsound reasoning! But when an attempt is made to substitute a system of rational therapeutics for the present chaos, we find that our foundations have still much of the character of a quicksand, and the stability of our 
superstructure must needs leave much to be desired. The very omens, moreover, look dark when we glance around with vague hope of encouragement. For by the irony of fate it happens that our most vaunted remedy at the moment is no other than that ancient household panacea-salt! Nor are there wanting modern evidences that even the justly condemned "local hæmatinics" above referred to could, after all, claim some slight justification on grounds quite other to those on which they were introduced. Frankly, we do not know whether to be more disheartened or encouraged by these troublesome "shiftings of the sands," but one sinful habit they do tend to confirm in us, namely, a steady reliance on well-grounded empiricism. Unfortunately, the treatment of hæmoptysis has not derived so much as might have been hoped even from this source-the effect of remedies has been too difficult to gauge in a bleeding whose origin is so dimly apprehended and whose course is so varied and uncertain.

Into this Slough of Despond the writer has felt himself impelled to probe, with the hope of finding some bottom on which a system of treatment might be based, without too overwhelming a sense of helplessness. Such results as emerge, if any do, he proposes to share herewith, for their sins, with the readers of TUBERCLE.

\section{Classification and Source.}

The first difficulty in the treatment of hæmoptysis arises, as would be expected, with the attempt to decide on the source, nature and causation of the bleeding. Not only is this question a clinical problem which must often remain undecided, but the very fundamentals of the matter seem hardly yet agreed on. Bleeding from eroded or ruptured vessels or from a miliary aneurysm in the wall of a cavity will be generally accepted as the explanation of a proportion of cases. But there remain also many exponents of capillary bleeding, whether in so-called "initial hæmoptysis," or as an accompaniment of inflammatory or "congestive" attacks. This may, as many suppose, be brought about by " diapedesis," but the possibility. of the rupture of capillaries under congestive stress can hardly be ruled out. The classification of Moeller, based on the character of the bleeding, takes two main types of case as its basis.

(a) Indirect or Passive Bleeding, where the blood comes up slowly, in moderate quantities, of dark, unaerated colour, and not frothy.

(b) Direct or Rupture Bleeding, where the blood comes with a rush, is "bright" coloured because fresh, whether of arterial or venous origin, abundant in quantity, and often foamy. In this connection it must be borne in mind that the pulmonary artery contains unaerated blood, while that in the vein is light coloured and "arterial"; the bronchial arteries and veins, on the other hand, form part of the systemic circulation.

This division is of value and would be still more so if we could be sure that capillary oozings were always of the character here described. Unfortunately, this is not entirely the case.

Thus Niemeyer accepted large hæmorrhages as possibly capillary. "The belief that a massive hæmorrhage cannot come from capillaries is untenable, since capillary bleedings from the nasal mucous membranes are not seldom so abundant as to threaten life." Sticker accepted this view, as did also Neumann. Focke, of Düsseldorf, ascribed nine-tenths of 
the cases to congestive bleedings, mostly from vessels in the bronchial mucous membrane, and Dührssen believed in capillary bleedings, mainly from ulcerated surfaces in the bronchial mucous membrane or cavity wall. Among recent writers Dumarest and Montgomery support capillary bleeding, and Jessen of Davos speaks of congestive bleeding (stauungs blutung) as an important factor. Bang of Copenhagen is also a believer in congestive bleeding. Certainly it is common to find "staining" or more during the "congestive attacks" which repeat themselves in certain cases of phthisis, and in this connection it is interesting that Flick puts forward "mixed infection" as an important factor. In addition, the bleeding which occasionally follows the too rapid removal of a pleural effusion covering a tuberculous lung must be largely of this nature. In a case seen recently by the writer airless blood was coughed out continuously but in moderate quantities over several days, and suggested a capillary origin-there was here none of the frank gushing which the views of Niemeyer would sanction! These capillary bleedings may be, no doubt, either parenchymatous or from the bronchial mucous membrane. Dührrsen described in addition a serious form of recurrent hæmorrhage leading to the formation of flesh-like casts of the bronchi, which are coughed out and followed by further serious hæmorrhage, the case going on to a fatal issue in most cases. The source of bleeding, in these cases, he ascribes to arteries in a bronchial wall stiffened by peribronchial tuberculosis. BirchHirschfeldt, who taught that pulmonary tubercle often begins in the medium-sized bronchi, describes such hæmorrhage from a bronchial vessel preceding death in one of his cases.

When we turn to the purely clinical aspect we find that decision as to the nature and source of the hæmorrhage is often difficult or impossible. A copious rush of dark-coloured blood may be presumed to come from the pulmonary artery, whether an eroded branch or a ruptured aneurysm. On the other hand, blood coming steadily in moderate quantities during a febrile exacerbation in pulmonary tuberculosis is probably a capillary bleeding. But between these two extremes there exists an infinite variety of conditions whose exact nature we have no adequate means of deciding. Some (as Stricker and T. F. Smith) have got over the difficulty of classification by dividing their cases according to the size of the hæmorrhage into three classes: "small," "considerable" and "large"; the latter writer adds to these the presumptive conclusion that the "small" (under 100 c.c.) are capillary bleedings, and the "large" (over 500 c.c.) come from a large vessel in a cavity, the "considerable" (up to 500 c.c.) being. from somewhat smaller damaged vessels. The most common working classification appears to be based on the division between "initial" hæmoptysis, and bleeding occurring at a later stage of the disease, and this seems useful where the former is really associated with early disease, and deep (and often unsuspected) cavitation can be ruled out. Thus Dübrssen makes a major division into "initial hæmoptysis,". and "hæmoptysis at later stages," and as subheadings to this latter gives:-

(a) Copious arterial bleeding in beginning of softening period.

(b) Arterial bleeding out of cavities.

(c) Capillary bleeding from ulcerated bronchial mucous membrane or ulcerating cavity. 
(d) Capillary bleeding without ulcerative changes.

This classification may serve as the basis for a few remarks under each heading. Penn Milton, in this country, suggests a somewhat similar classification which we may consider as we go along.

\section{(1) INITIAL HAMOPTYSIS.}

This may be due in some cases to erosion or rupture of vessels in a tuberculous centre, and in this case may represent the commencement of the "open stage" of tuberculosis. This fact is exemplified by the appearance of tubercle bacilli in the sputum which follows the bleeding-among 239 soldiers with hæmoptysis as the first sign of tuberculosis, 158 showed bacilli in the sputum within fourteen days of the attack (Stricker). More commonly, in all probability, we have here to do with a congestive capillary oozing. Initial hæmoptysis occurs, according to Reiche, in $9 \cdot 2$ per cent. of cases of phthisis (among 1,952 cases), and is just twice as common in men as in women; many put the incidence of initial hæmoptysis at a higher figure. It accounts for somewhere about one-third of all cases of hæmoptysis. Though an initial hæmoptysis is no unfavourable occurrence, since it brings the patient promptly under medical supervision, yet it appears to indicate a predisposition towards further bleedings. According to Reiche 57.9 per cent. of cases with initial hæmoptysis have further bleedings, while the incidence of other cases of phthisis amounts to about 31.4 per cent. This question of the tendency of some cases to bleed and of others to escape bleeding, in spite of rapid softening and of cavitation, we will return to later.

\section{(2) HæMOPTYSIS AT LATER STAGES.}

(a) At the beginning of the softening period, and this appears to correspond with a second stage group indicated by Milton. This may be a time of very dangerous or fatal bleeding-there may be a softening apical lesion, but, on the other hand, fresh inflammation and softening may have occurred in older areas. These cases are of necessity febrile, both before and after the attack, since they are essentially cases of active disease.

(b) Arterial bleeding out of cavities, either from rupture of a pulmonary aneurysm, or of unobliterated twigs of the pulmonary artery running through the vomica. A few writers, as Jessen, appear to regard rupture of a miliary aneurysm as a fatal occurrence; but most take a more favourable view and allow that recovery may and often does take place. Patterson is even congratulatory over the event, "because the aneurysm has burst, and the weak point on the blood-vessel obliterated." This is a position which can no more be disputed than supported, as we cannot tell in any individual case (unless fatal) whether an aneurysm is present or not. But in any case it must be admitted that direct fatalities from hæmoptysis are by no means common: Brehmer recorded 16 among 14,000 patients, Reiche but three "among many thousand cases," Wolff three in 1,200 cases, Sticker four in 900 tuberculous soldiers, Schröder three among 1,100 cases. The dangers from aspiration pneumonia are more serious than those from the immediate hæmoptysis 
(c) and $(d)$ may well be grouped together as:

Capillary bleeding from bronchial mucous membrane or cavity walls, since we cannot tell if these are ulcerated or not, and to this may be added, perhaps, parenchymatous bleeding. Milton has no corresponding group in his classification but adds a further group which may partly cover this and of which we shall speak shortly. Dührrsen finds this the commonest of all groups in chronic phthisis, and describes the blood as generally free of air, compact, clotted and mixed with mucus or pus. It seems likely that this is the "congestive bleeding" of many other authors, ascribed by Bang to an inflammatory process or a "fluxion" to the lungs, and in relation with which Flick would associate a mixed infection. In this connection it is interesting that Bang found 45 per cent. of his hæmoptysis cases (159 of 354 cases) showed evidence of inflammatory conditions, mostly indicated by fever at the time of the bleeding. How many of these cases were febrile because they belonged to our Groups (1) and (2a) we have no means of telling, but there is no doubt that " congestive attacks," characterised by fever and increased sputum and often confined to a fortnight's duration, play an important rôle in the group under consideration. In such attacks stained sputum is common and hæmoptysis of almost any grade may occur.

The last group to which we shall refer is that described by Penn Milton under the heading Hrmoptysis at any stage in plethoric subjects. He points out how often repeated hæmoptyses of moderate size are associated with arrested disease in subjects who are overfed and of gouty disposition. These attacks are familiar to most of us and may be due in many cases, as he suggests, to engorgement of lung and diapedesis. These subjects are often the victims of the congestive attacks mentioned above and this may account for Milton's omission of the group just described. Since most subjects of the group now under discussion form fibrous tissue with "avidity" these cases often present the combination of considerable fibrosis, dry cavities, and often bronchiectasis. Here we have ideal conditions for mixed infections and "catarrhal attacks," and also innumerable possible sources of bleeding. Hence, the source of the blood must always be doubtful, and to the congestive explanation suggested by Milton one might add rupture of small vessels from contraction of fibrous tissue, and also, in the more copious bleeding, possibly the rupture of miliary aneurysms. It seems likely that Patterson's cases cited above belonged to this group, and may have had a mixed explanation. Sticker has a good deal to say about this group under the heading of "Arthritic constitution," and the writer has no doubt that the association with cardio-vascular changes, full blood-pressure, and other conditions commonly summed up under the heading "Gouty diathesis" is a real one. In this connection it is interesting that Andrew Clark, being struck with recurrent bleedings in cases of healed lung disease, was able to demonstrate that in certain people over 50 hæmoptysis may result from peculiar vascular changes, amorphous and hyaline degeneration of the media and intima, and small cell infiltration in the media of end arteries in the lung, apart from pulmonary tuberculosis. He reported three such cases in 1889 and likened the changes in the vessels to those which occur in osteo-arthritic joints, with which the condition was found associated. He did not think that the changes were 
those of ordinary arterio-sclerosis, so it is doubtful whether his cases correspond with the group under discussion, though Sticker makes his "arthritic constitution" cover arterio-sclerotic changes and all the other conditions we are apt to collect together as "gouty." Lancereaux and Huchard described cases similar to those reported by Andrew Clark.

\section{Factors in Cadsation.}

And now, having made such classification as seems possible with the somewhat limited knowledge we at present possess, we are faced with certain abnormalities in the incidence of hæmoptysis which have so far baflled investigation. In the first place certain individuals, among cases of phthisis, tend to bleed, perhaps repeatedly, while others with similar or worse lesions escape hæmoptysis altogether. In the second place it appears that the incidence of hrmoptysis shows a variation with weather and season and possibly with other environmental conditions. In large institutions the cases have been observed to occur in "waves," and investigation has been directed to this phenomenon, though so far with uncertain results.

Two factors have always stood out obviously as possibly responsible alike for these individual differences and for mass fluctuations, one the coagulation power of the blood, and the other the blood pressure. To these, as regards individual tendency to bleed, may now be added a possible third factor. As long ago as 1907 Cornet was suggesting that certain secondary bacteria might be responsible for tendencies to hæmorrhage in certain cases (Vielleicht spielen hier gewisse sekundäre Bakterien eine Rolle); lately the occurrence of broncho-pulmonary spirochætosis has seemed to justify this suggestion.

\section{(1) SPIROCHATTOSIS.}

Originally described as a tropical disease, it has of recent years been recognized in Europe and in this country ; in cases, moreover, which have never visited the tropics (Leslie Brown, Lancet, May, 1920. Campbell Faill, Tubercle, June, 1921). In tropical regions periodic hæmoptysis occurs in cases where the evidences are against tuberculosis, and where the sputum teems with (? Vincent's) spirochætes and Bacillus fusiformis. Sinclair, of Hawaii, investigating the matter in relation to pulmonary tubercle, found the spirochæte present in 256 among 410 cases. Of these 256, 71 per cent. suffered with hæmoptysis, while of the remaining 154 cases in which the spirochæte was absent only 36 per cent. suffered with hæmoptysis. Put otherwise, among 238 cases of hæmoptysis spirochætes were present in 76 per cent., while among 172 cases̀ without hæmorrhage they were found in but 43 per cent. Sinclair remarks that hæmorrhage in incipient cases rarely occurs unless where the spirochrete is present. If this result were confirmed we might here have at hand an explanation of a matter which has always been baffling-namely, why, with similar lesions, bleeding should be frequent in one case and entirely absent in another. The matter seems worthy of investigation in this country.

(2) CLOTTING POWER.

v. Hösslin found blood in cavities remains fluid, and Magnus-Alsleben that fresh tuberculous lung tissue delays or hinders clotting, while 
fresh normal tissue accelerates it greatly. So efficient is this latter effect that in the dog, whose coagulation time is short, it is impossible to produce a fatal result even when the main arterial branch to a lobe is cut (Wiggers). Bode found the clotting power for tuberculosis compared to other diseases high; Hess normal. Fonio found the coagulation time normal, but the coagulation power lowered (as tested by drawing off blood from vein into solution of magnesium sulphate and noting concentration which permits and which stops coagulation). It might be argued that the differences in the tendency to hæmoptysis in phthisis bear no relationship to the disease itself, but depend on the original good or poor clotting power of the patient, and that this is affected by individual (as menstruation) and environmental (as weather) influences. Stähelin, employing Fonio's method, thought he could establish a lower clotting power for " bleeders" than for " non-bleeders."

The effects of various influences on clotting power may be collected as follows:-

Food.-In this connection it is said that many hæmoptyses start in the early morning hours. It was thought by Van den Velden that the shortened coagulation power produced by sodium chloride (and to be discussed more fully later) was due to its osmotic effect, and the flowing into the blood-stream of tissue fluids bearing the coagulation-increasing ferment (thrombokinase). On the same lines the coagulation power should increase after meals, and both Bürker and Hartmann found that this was the case, but Stähelin was unable to confirm it. Menstruation. Sorgo noted that hæmoptysis commonly started at the menstrual period and attributes this to vasomotor disturbances. Sabourin noted congestion in areas of lung disease during the menstrual period and hæmoptysis as a common accompaniment ( $?$ hence also the common premenstrual fever.) Stähelin finds clotting power in menstruating women various. Fever.-No change in coagulation power was found as a result of this by Hartmann, Nèl, Rudolf-Cole, Solis-Cohen, and Stähelin. Hæmoglobin content of blood.- It is generally agreed that clotting power rises as hæmoglobin falls. Where the loss is due to hæmorrhage this may be explained by the "thrombokinase" theory mentioned above; the explanation in anæmia of chronic disease is not so clear. Weather. - Strandgaard found a relationship between hæmoptysis and humidity of the air, and Janssen agreed and held that the influence of direction of wind was bound up in the question of moisture. Gabilowitsch attached more weight to barometer movements (i.e., atmospheric pressure as such) and especially to the rapidity of the changes. These weather alterations have been found to effect both blood-pressure (Strandgaard) and coagulation power (Stähelin). Stähelin, who set out to prove the relationship of coagulation power to hæmoptysis, is at the end very reticent in his conclusions. $\mathrm{He}$ inclines to include with clotting power, also changes of blood concentration (vaso-motor), and of blood-pressure, and suggests that the secret of changing tendencies to bleed may, after all, lie in the washing in and out of the blood-stream, under various conditions, of tissue fluid, and therewith thrombokinase," as was suggested by Van den Velden. 


\section{(3) BLOOD-PRESSURE.}

The influence of general blood-pressure on hæmoptysis has been very variously estimated. $H$. Naumann (1904) examining the pressure in 100 cases of phthisis found a higher average among those suffering with hæmoptysis. Barbary (1905) found the pressure raised before the bleeding. W. Müller (1910) always found a steady rise of pressure up to the moment of hæmoptysis, and thought the bleeding might be prevented by measures which lowered the pressure. Jacquerod, on the other hand, found lower pressure in bleeders than in other cases of phthisis. But more potent than all these temporary slight changes must be the effects of exercise and work on the systemic blood-pressure (and blood flow!) and these, perhaps naturally, have been credited with the immediate causation of hæmoptysis by most physicians of the past. Latterly this doctrine has been opposed on grounds both of "experience" and of "reasoning." On the side of "fact" it is pointed out that most bleedings occur during sleep or rest, and.but few during exercise or exertion. Bang found 69 per cent. of his cases started bleeding while in bed or in a deck chair, and on comparing the durations of rest and exercise in his sanatorium he arrived at the conclusion that "the distribution of the bleedings is a function of time and not of occupation." Moreover, in cases where bleeding had already occurred he did not find that exertion was any factor in its continuance or recurrence.

On the side of "reasoning" we are warned that the assumed rise of pulmonary pressure consequent on a rise of systemic blood-pressure has no basis in fact. It has been generally held that the aortic pressure maintains itself at some two-and-a-half to three times that of the pulmonary artery, but when variations of pressure occur, these, according to recent work, do not show much parallelism between the two systems. The changes may run in the same direction, but they may also vary independently, or even go in the opposite direction. Certainly aortic pressure may vary within wide limits without affecting the pulmonary pressure, as was observed by Knoll, Weber, Tigerstedt, and others, but Fühner and Starling have pointed out that if the change is prolonged the relationship of pressure between the two systems tends to be maintained. It will be noted that all the argument here put forward has been directed to pulmonary blood-pressure, to the ignoring of pulmonary blood flow. It appears, however, that it must be a very decided as well as long lasting rise of pressure notably to affect the pressure in the pulmonary artery, so distensible a "sac" is the pulmonary circulation. For Lichtheim (in 1875) showed that cutting out the lung circulation up to 75 per cent. caused no change in the systemic blood-pressure, the remaining 25 per cent. was sufficient to maintain the blood flow. He also showed that a pneumothorax causes no notable effect on pressure, and this was confirmed by Tigerstedt, Gerhardt, Bradford and Dean, and others. Tigerstedt ligatured the root of one lung with similar results, remarking, "The fact of the constancy of pressure in the greater circulation after elimination of one lung lies in the fact that the remaining portion of the lesser circulation suffices to feed the left heart with much the same volume as before." This remarkable power of accommodation to gross changes is certainly suggestive of a vasomotor effect; nevertheless the presence of 
vasomotor nerves in the lung has been denied by some physiologists (notably Brodie and Dixon, Gerhardt, Velich, Knoll, \&c.), but is now accepted by most (Cloetta, Beresin, Fühner and Starling, Schäfer, Weber, Wiggers, \&c.).

\section{The Pulmonary Circulation.}

The views held about the pulmonary circulation are still somewhat conflicting, and this is unfortunate from the point of view of the present subject. A short account will be attempted here and further details will emerge under the headings of various drugs employed in treatment.

The lungs present, as is obvious, a whole cross-section of the circulation; the blood must pass for this to be maintained, the two factors in this being the blood-pressure and the size of the vessels. The latter is regulated, let us admit, by a somewhat poorly developed vasomotor system (Bradford and Dean), and this will affect, mostly, the whole area at once rather than act, as in the systemic circulation, as a local phenomenon. Obviously under these conditions the major effects must come from two outside factors: (1) The supply of blood from the systemic circulation flowing into the right auricle; (2) the clearing of the left auricle-if the left ventricle does not empty itself then pulmonary congestion must arise. 'These two factors are likely to act together for better or for worse, the dominating influence being found in the hurrying up or slowing down of the general circulation as a whole. For where a greater bulk of blood is in motion both entrance and exit of the pulmonary circulation are likely to be crowded (E. Weber). It is this factor of blood flow through the lungs, as distinct from pulmonary pressure, which seems to have been ignored by the advocates of ambulant treatment, for exercise must surely set up an increased circulation through the lungs and provide conditions favourable to hæmoptysis. Acceleration or retardation of the systemic circulation being the key to pulmonary blood flow, the matter may be outlined as follows:-

Increased supply of blood to the pulmonary area will be caused by a general increase of systemic pressure (adrenalin) whereby an increased flow occurs through areas of feeble vasomotor power (the brain, \&c.), or by widening of some vascular area without a rise of pressure (kidney vessels under caffein and salt), or by both these effects combined, as under sustained muscular exertion. May not this also be the explanation of cases of hæmoptysis at the menstrual period?

Diminished supply of blood may occur as a temporary phenomenon through holding up the blood in some important systemic fields (as by binding limbs or large cups to abdomen in hæmoptysis). Lowering of general blood-pressure is of doubtful effect. An increase of bleeding from a lung wound was observed by Frey after giving amyl nitrite, as a result, he thought, of backward pressure. Obviously the pulmonary blood flow could not be diminished by a pulmonary vaso-constriction (presuming that such occurs) unless the right heart gave out, since the circulation must be kept going. Drugs which act on the heart, like aconite and emetine, may perhaps (? within the limits of safe administration) retard and diminish for a while the pulmonary circulation.

The conclusion to which this cursory examination would seem to lead 
us is as follows : Firstly, that it is rather blood flow than arterial pressure which should concern us in the consideration of pulmonary circulation qua hæmoptysis; and secondly, that in this complaint drugs which act on the circulation are likely to avail us but little. We can, it is true, increase the pulmonary circulation by hastening the general blood-flow, but our means of diminishing this blood-flow are less clearly adequate. Nor can we exert any local stopcock action in the pulmonary field as can be done in the systemic area. Such measures as we have must act on the pulmonary circulation as a whole, unless indeed a more localised effect can be claimed for the icebag (q.v.), and excepting also such mechanical effects as are obtained by collapse of a bleeding lung. These matters will be returned to when the question of treatment is considered.

(To be continued.)

\section{TUBERCULOSIS IN CHILDHOOD.}

\section{A New Clinical Sign.}

By F. Stanley Tinken, M.B.Camb.

Mèdical Superintendent, Barrowmore Hall, Cheshire.

Tubercolosis in childhood is for the main part a glandular disease. True disease of lung tissue, diagnosable by clinical signs, is comparatively rare. The disease is most frequently found in the group of glands surrounding the main bronchus. These glands doubtless receive the lymphatic drainage from the lung tissue itself, and according to Ghon it is from the lung tissue itself that the tubercle bacillus reaches these glands. Whether this is the origin of the infection or not matters little so long as the extension of the disease in the lung tissue itself does not extend to large proportions. Another source of infection of the bronchial glands appears to be much more likely, and the effect of naso-pharyngeal disease in the forming of nasal obstruction, enlarged adenoids and tonsils and sepsis thereof, produces a series of clinical signs in the chest which might easily be, and very often are, mistaken for pulmonary disease.

In nearly every case of nasal obstruction one finds the following clinical signs: a dullness at one or other apex, more especially the right, the proportion approximating 2 to 1 ; a lack of air entry over the upper portion of the right upper lobe; a reduction in Krönig's isthmus and a slight sinking above and below the clavicle. This has, I believe, been attributed chiefly to mechanical causes; but I will suggest the probability that where sepsis occurs in children in the naso-pharynx, by contiguous infection and inflammation of tracheal and bronchial mucosa, a corresponding enlargement of the bronchial glands results, producing an alteration in the lymphatic return from that portion of the lung served by that particular gland, the adenoid and naso-pharyngeal condition acting upon the bronchial glands in exactly the same way as tonsillar inflammations react upon the cervical glands. 